\title{
О ВОЗМОЖНОСТИ УПРАВЛЕНИЯ ПРОЦЕССОМ РАСХОДОВАНИЯ РЕСУРСА ТЕХНИЧЕСКИМ ОБЪЕКТОМ
}

\author{
Воинова С. А. ${ }^{1}$ \\ ${ }^{1}$ Одесская национальная академия пищевых технологий, Одесса \\ E-mail: voinova_s@yahoo.com
}

Copyright (C 2014 by author and the journal “Automation technological and business - processes". This work is licensed under the Creative Commons Attribution International License (CC BY). http://creativecommons.org/licenses/by/4.0/

(c) (i) $\begin{aligned} & \text { ONAFT } \\ & \text { Open Access }\end{aligned}$ DOI: $10.15673 /$

\begin{abstract}
Аннотация
Значительная часть промышленного оборудования отработала парковый ресурс, поэтому функционирует с низкими показателями технологической эффективности. Это придало задаче управления процессом расходования техническими объектами своего ресурса особую актуальность, превратило ее в важную научно- и организационно-техническую проблему. Современные методы, пути и средства анализа текущего состояния нового технического объекта позволяют оценить его состояние и назначить его парковый ресурс, позволяют оценить остаточный ресурс действующего технического объекта. Появилась возможность применения арсенала современных технических мер воздействия на технический объект, для управления процессом его движения по траектории расходования ресурса. Для реализации программы действий по управлению процессом расходования техническими объектами ресурса, необходмы высокий профессиональный уровень специалистов и надлежащее ресурсное обеспечение составляющих программы.
\end{abstract}

\section{Abstract}

The major part of the industrial equipment has fulfilled a resource, therefore it functions with low parameters of technological efficiency. It has given to a problem of management of process of an expenditure by technical objects of the resource a special urgency, has transformed it in important scientific- and an organizationaltechnical problem. Currently available methods, ways and means of the analysis of a current condition of new technical object allow to estimate its condition and to appoint its resource, allow to estimate a residual resource of operating technical object. There was a possibility of application of an arsenal of modern technical measures of influence on technical object, for management of process of its movement on a trajectory of an expenditure of a resource. For realization of the program of actions on management of process of an expenditure of technical objects of a resource, the high professional level of experts and appropriate resource maintenance of components of the program are necessary.

\section{Ключевые слова}

Возможности, управление, процесс, расходование, ресурс, технический объект.

В нынешних условиях, на пути к инновационному сценарию развития производства в Украине, предстоит некоторый период использования во всех отраслях, в том числе в пищевой промышленности, ныне 


\section{I ПИТАННЯ ТЕОРІЇ, МЕТОДИ ТА АЛГОРИТМИ ЕФЕКТИВНОГО АВТОМАТИЧНОГО УПРАВЛІННЯ ОБ'ЄКТАМИ ХІМІКО-ТЕХНОЛОГІЧНОГО ТИПУ}

действующего оборудования, отработавшего 1,5-2 и более парковых ресурса и претерпевшего, вследствие этого, значительный износ.

Уровень показателей технологической эффективности изношенного оборудования существенно уступает уровню показателей аналогичного отечественного и зарубежного оборудования, располагающего остаточным ресурсом, и, особенно, уровню показателей нового, современного оборудования.

Наблюдаемые низкие показатели функционирования изношенного оборудования обусловливают крупный суммарный общехозяйственный ущерб, проявляющийся в виде низких экологических, экономических и общетехнических показателей осуществляемого технологического процесса. В связи с этим сформировалась важная, сложная и безотлагательная проблема нормализации сложившейся обстановки.

Комплекс аналогичных по характеру задач, требующих решения во всех отраслях производства, приобрел системный характер и сформировал научно- и организационно-техническую проблему повышения уровня технологической эффективности функционирования производства. Проблему характеризует государственный уровень актуальности и значения, а ее содержание представляет собой сложную комплексную межотраслевую программу научно- и организационно-технических мероприятий и работ.

Как показывает анализ сложившейся обстановки, решение задач указанной проблемы целесообразно осуществлять в нынешних условиях в виде межотраслевой программы, состоящей из двух частей:

- первая часть: повышение уровня технологической эффективности (ТЭ) действующего изношенного оборудования доступными средствами;

- вторая часть: замена изношенного оборудования новым, современным, инновационно-насыщенным.

Особенности первой части:

- относительно малые ресурсовложения в выполнение программы работ,

- относительная краткость периода выполнения работ,

- существенное повышение уровня ТЭ оборудования,

- высокая удельная (приходящаяся на единицу затрат) эффективность ресурсовложений.

Особенности второй части:

- крупные ресурсовложения в осуществление программы;

- значительная длительность периода выполнения работ;

- повышение уровня ТЭ оборудования до мирового уровня;

- высокая удельная эффективность ресурсовложений в осуществление программы.

В нынешних условиях в Украине практический интерес представляет первая из указанных частей. Рассмотрим кратко ее основные возможности.

Существующее оборудование, действующие технические объекты (ТО), обладают ТЭ, содержащей следующие три составляющие: экологическую эффективность $\left(\mathrm{E}_{\text {л }}\right)$, экономическую эффективность (Е общетехническую эффективность (Еоб $)$ [1]:

$$
\left(\mathrm{E}_{\mathrm{T}}\right)=\mathrm{f}\left\{\left(\mathrm{E}_{\text {л }}\right),\left(\mathrm{E}_{\mathrm{H}}\right),\left(\mathrm{E}_{\text {общ }}\right)\right\} \text {. }
$$

В процессе эксплуатации, от момента ввода в действие, ТО испытывает нарастающее во времени негативное воздействие процесса износа. Вследствие этого, уровень его ТЭ непрерывно снижается, от исходного уровня $\mathrm{E}_{\text {и }}$

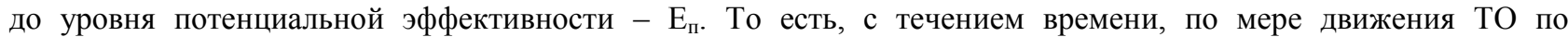
траектории расходования «запаса» своей ТЭ (траектории расходовании ресурса), износ обусловливает ущерб, наносимый ТЭ объекта, равный в момент времени $\mathrm{T}_{\mathrm{i}}$

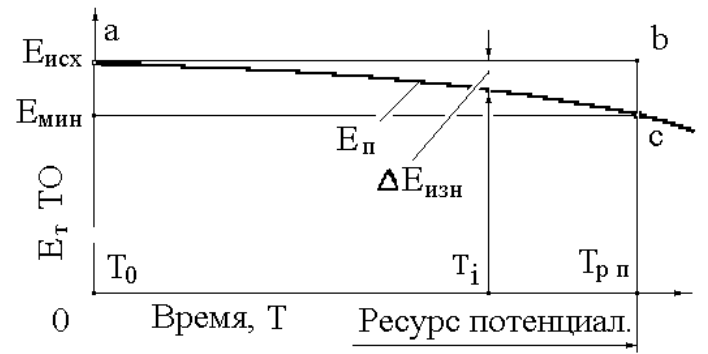

Рис. Влияние износа ТО на изменение его технологической эффективности во времени

$$
\Delta \mathrm{E}_{\text {изн }}=\mathrm{E}_{\text {и }}-\mathrm{E}_{\text {пा }}
$$

При снижении уровня $\mathrm{E}_{\text {п }}$ до минимально допустимого уровня $\left(\mathrm{E}_{\text {мин }}\right)$, ТО переходит в предельное состояние, исчерпывается потенциальный ресурс его работоспособности $\left(\mathrm{T}_{\mathrm{p} \text { п }}\right)[2]$.

Таким образом, ресурс ТО зависит, в конечном счете, от воздействия двух факторов: интенсивности износа и уровня $\mathrm{E}_{\text {мин. }}$.

Важный технологический параметр ТО - уровень его $\mathrm{E}_{\text {мин }}$ устанавливает завод-изготовитель ТО. При этом, подход и процедура назначения этого параметра свойств ТО 


\section{$\underline{1}$ ПИТАННЯ ТЕОРІЇ, МЕТОДИ ТА АЛГОРИТМИ ЕФЕКТИВНОГО АВТОМАТИЧНОГО} УПРАВЛІННЯ ОБ'ЄКТАМИ ХІМІКО-ТЕХНОЛОГІЧНОГО ТИПУ

регламентированы нормативными положениями и документами. В принципе, инструмент определения уровня $\mathrm{E}_{\text {мин }}$ ТО относительно его выбранного конкретного технологического свойства объекта разработан и практически достаточно продуктивно применяется.

Несравненно более сложно выглядит задача установления влияния процесса износа ТО на его остаточный ресурс. Усложнение вызвано следующими причинами:

1) Износ ТО проявляется в виде множества негативных разнородных изменений его технологических свойств. Изменения прогрессируют во времени, накапливаются, нанося все возрастающий ущерб технологическим свойствам объекта. Изучение существа составляющих процесса износа ТО, закономерностей их протекания - предмет технической геронтологии [2, 3].

Есть основания считать, что накопленные сведения и масштаб научных изысканий в проблематике износа ТО не соответствуют масштабности проблемы износа ТО и ее значению.

2). Технологические свойства ТО можно отразить множеством технических показателей (параметров) экологического, экономического и общетехнического характера.

Согласно сложившемуся подходу, из множества показателей состояния ТО выбирают главный. По уровню этого показателя в момент рассмотрения судят о текущем состоянии объекта. На основании этих данных оценивают его остаточный ресурс.

Однако, в реальных производственных условиях в суждении об остаточном ресурсе часто поступают формально: сопоставляют назначенную (заводом-изготовителем) длительность паркового ресурса ТО с длительностью периода его работы к моменту рассмотрения вопроса. По рассчитанной разности указанных периодов оценивают остаточный ресурс.

В реальных условиях эксплуатация ТО ведется в режимах, в той или иной степени отличных от регулярного режима, на который опирался завод-изготовитель. Поэтому указанный выше формальный подход к оценке остаточного ресурса ТО следует признать несостоятельным.

Как показывает опыт, прогнозировать динамику процесса износа ТО трудно даже применительно к случаю работы его в регулярном (расчетном, проектном) режиме. Данная задача непомерно усложняется в реальных условиях, а именно, случае работы ТО в нерегулярном режиме, когда на него воздействуют негативные случайные факторы: в частности, отклонения от эксплуатационного регламента, нарушения режима технического обслуживания, технические происшествия, аварии и т. п.

Кроме отмеченных, воздействующих негативно случайных факторов, на ТО также могут воздействовать позитивные детерминированные факторы - частичное обновление ТО [4].

3. Оперативный контроль фактического (текущего) состояния ТО в заданный момент времени, как правило, является весьма сложной организационно-технической задачей. Это обусловлено трудностью и сложностью измерения уровня (выбранного заводом) главного показателя состояния (свойств) ТО и оценки его остаточного pecypca.

В нынешних условиях производства (в каждый произвольный момент времени) часто возможно лишь использование доступных косвенных показателей состояния ТО. На основании этих сведений возможно не измерение, а лишь экспертная оценка остаточного ресурса ТО. Принципиальные недостатки подобного подхода к анализу фактического состояния ТО и его остаточного ресурса очевидны.

Проблема изучения комплекса воздействий на ТО, обусловливающих протекание процесса его износа, приобретает особую актуальность.

В нынешних условиях приближения к инновационному сценарию развития производства необходимо располагать научно-методическим инструментом, позволяющим с надлежащей точностью назначать парковый ресурс создаваемого ТО, анализировать текущее состояние ТО, определять размер остаточного ресурса действующего (частично изношенного) ТО.

Для разработки и использования этого инструмента, необходимо осуществление программы научно- и организационно-технических изысканий по проблеме управления износом ТО. Необходимо исследование закономерностей процесса износа ТО под воздействием разных факторов и их сочетаний. В этом направлении необходимо решить следующие задачи:

- расчет и назначение ресурса создаваемого ТО,

- оперативные обследование и анализ текущего состояния действующего ТО, с позиций оценки уровня его работоспособности (по разным параметрам состояния, технологическим свойствам),

- определение остаточного ресурса действующего ТО.

Речь идет об изучении и использовании факторов, воздействующих на ресурс ТО системно.

Рассмотренные вопросы находятся в сфере технической геронтологии. Экологический аспект занимает в них приоритетное положение. 


\section{I ПИТАННЯ ТЕОРІЇ, МЕТОДИ ТА АЛГОРИТМИ ЕФЕКТИВНОГО АВТОМАТИЧНОГО} УПРАВЛІННЯ ОБ'ЄКТАМИ ХІМІКО-ТЕХНОЛОГІЧНОГО ТИПУ

В целом, решение указанной задачи открывает возможность управления процессом движения ТО по траектории расходования им своего ресурса.

При этом важным является корректное обращение с понятием и, соответственно, с отражаемым им параметром состояния ТО, - степенью (уровнем) его износа.

Необходимо отметить то, что сложность и высокая размерность процесса износа ТО, обусловленные влиянием множества разнородных факторов, усложняет, сдерживает развитие научно-технических изысканий по проблеме износа ТО.

Развитие подобных изысканий характерно для сферы использования технологий и техники, связанных с повышенным уровнем опасности для участников производства. Характерной являются сферы применения транспортных средств, взрыво- и пожароопасных производств. Однако, в расширенной разработке проблемы износа нуждаются все без исключения сферы современного производства.

Анализ состояния основных фондов отечественного производства позволяет считать целесообразным выполнение межотраслевой программы проводимых научно-технических изысканий в следующих направлениях:

1. Исследование закономерностей процесса износа ТО с учетом влияния действующих факторов разного рода и эффектов их взаимодействия.

2. Исследование и разработка подходов, методов и средств оперативного (и учетного) контроля над состоянием ТО, позволяющих с надлежащей точностью оперативно оценить его остаточный ресурс.

3. Использование результатов выполнения программы для повышения качества управления процессом износа оборудования. На основе этого повысить уровень технологической эффективности действующего оборудования.

Степень износа значительной части отечественного промышленного оборудования, в том числе пищевой промышленности, обусловило актуальность проблемы его обновления. Осуществляемое частичное обновление изношенных ТО часто носит стихийный характер, а получаемый положительный результат не всегда оправдывает ожидания и вложенные ресурсы $[4,5]$.

Возможности управления процессом расходования ТО ресурса работоспособности таят в себе определенные резервы повышения уровня технологической эффективности действующего оборудования независимо от степени его износа. Это положение имеет принципиальное значение.

Программу работ по полному или частичному обновлению изношенных ТО необходимо поставить на прочную научную основу. Реализация программы возможна при условии обеспечения высокого профессионального потенциала исполнителей и при надлежащем объеме ресурсных вложений в ее осуществление.

\section{Выводы}

1. Решение задач проблемы управления процессом износа ТО необходимо интенсифицировать;

2. Необходимо расширить разработку подходов, методов и средств текущей оценки состояния ТО, степени их износа, размера остаточного ресурса;

3. Целесообразно расширить блок программно-методического обеспечения научно-технических изысканий в сфере изучения проблемы износа ТО;

4. Целесообразно сформировать подходы к созданию САУ процессом износа ТО, конкретно, к каждым их классам, системам и видам;

5. При разработке заводом-изготовителем ТО комплекта сопроводительной документации необходимо надлежащее внимание уделить задаче контроля над текущим состоянием ТО, над режимом расходования объектом своего ресурса;

6. То же целесообразно сделать в комплекте отчетных документов, представляемых владельцем ТО руководящему, контролирующему органу;

7. Контроль над научно-технической культурой в сфере учета расходования ресурса ТО необходимо поднять до современного уровня и обеспечить оценку в данной сфере со стороны технических инспекций и руководства промышленными объектами;

8. Целесообразно расширить объем и характер научно-технических изысканий по проблеме износа, проводимых отраслевыми научными структурами, скоординировать их работу, расширить ресурсовложения в разработку проблемы износа ТО. 


\title{
1 ПИТАННЯ ТЕОРІЇ, МЕТОДИ ТА АЛГОРИТМИ ЕФЕКТИВНОГО АВТОМАТИЧНОГО
} УПРАВЛІННЯ ОБ'ЄКТАМИ ХІМІКО-ТЕХНОЛОГІЧНОГО ТИПУ

Литература

1. Воінова С.О. Можливості підвищення надійності технічних об'єктів з малим залишковим ресурсом/ Прогресивні техніка та технології харчових виробництв ресторанного господарства і торгівлі: Зб. наук. пр./ Хар. держ. ун-т харчування та торгівлі.- Харків, 2009. - Вип. 1(9).- С. 307 - 313;

2. Воинова С.А. Особенности формирования ресурса технических объектов/ Енергетика та електрифікація, №10, 2012.- С. 40 - 43;

3. Воинова С.А. Техническая геронтология. Потенциал влияния на эффективность функционирования технических объектов/ Матер. за VI Международна научна практична конференция «Найновите постижения на европейската наука-2010», 17 - 25 юни, 2010г. Том 20 «Технологии. Физическа култура и спорт».- София: «Бял ГРАД-БГ» ООД, 2010. - С. 79 - 84;

4. Воинова С.А. Обновление как инструмент развития производства/ Известия вузов и энергетических объединений СНГ, № 2, 2013.- С. 69 - 74;

5. Воинова С.А. Сокращение влияния износа на технологическую эффективность технических объектов/ Новые и нетрадиционные технологии в ресурсо- и энергосбережении.- Матер. научно-техн. конф., Одесса, 9 - 10 сент. 2010.- Одесса-Киев: АТМ Украины, 2010.- С. 27 - 31.

\section{НЕСОБЛЮДЕНИЕ ЗАКОНА ИСКЛЮЧЕННОГО ТРЕТЬЕГО В НЕЧЕТКОЙ ЛОГИКЕ И ТЕОРИЯ ПРИНЯТИЯ РЕШЕНИЙ В УСЛОВИЯХ НЕОПРЕДЕЛЕННОСТИ}

\author{
Волков В.Э. ${ }^{1}$ \\ ${ }^{1}$ Одесская национальная академия пищевых технологий, Одесса \\ E-mail: victor@te.net.ua
}

Copyright (C) 2014 by author and the journal “Automation technological and business - processes”. This work is licensed under the Creative Commons Attribution International License (CC BY). http://creativecommons.org/licenses/by/4.0/

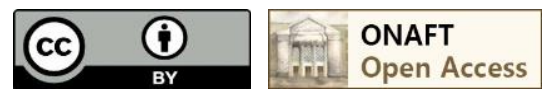

DOI: $10.15673 /$

\begin{abstract}
Аннотация
Рассмотрен вопрос о несоблюдении закона исключенного третьего в нечеткой логике. Показана необходимость применения нечеткой логики и теории принятия решений в условиях неопределенности в системах поддержки принятия решений для управления сложными объектами, в частности потенциально взрывоопасными объектами.
\end{abstract}

Abstract

Nonobservance of the rule of excluded third for fuzzy logic is considered. The necessity or the fuzzy logic usage and application of the decision under uncertainty theory for the control of complicated objects, especially of the dangerously explosive objects are proved. 